\title{
Parathyroid Hyperplasia
}

National Cancer Institute

\section{Source}

National Cancer Institute. Parathyroid Hyperplasia. NCI Thesaurus. Code C3989.

A hyperplasia of the parathyroid gland. 